\title{
Fracture toughness as an alternative approach to quantify the ageing of insulation paper in oil
}

\author{
C. Fernández-Diego • I. A. Carrascal • A. Ortiz • I. Fernández • \\ D. Ferreño $\cdot$ S. Diego $\cdot$ A. Casado
}

Received: 10 July 2021 / Accepted: 25 September 2021 / Published online: 20 October 2021

(C) The Author(s) 2021

\begin{abstract}
Oil-immersed transformers use paper and oil as insulation system which degrades slowly during the operation of these machines. Cellulose materials are used generally as insulation solid in power transformers. The degree of polymerization (DP), defined as number of repeating $\beta$-glucose residues in the cellulose molecule, is a critical property of cellulosic insulation material used in transformers, since it provides information about paper ageing and its mechanical strength. The fast-developing electric power industry demanding superior performance of electrical insulation materials has led to the development of new materials, as well as different drying techniques performed during transformer manufacturing and service when required. Both developments have caused some practical difficulties in the DP measurement. Moreover, the increasing interest in synthetic dielectric materials replacing cellulose materials requires measuring alternative properties to
\end{abstract}

C. Fernández-Diego ( $($ ) · A. Ortiz · I. Fernández Electrical and Energy Engineering Department, School of Industrial and Telecomunications Engineering, University of Cantabria, Avenida Los Castros, 39005 Santander, Cantabria, Spain

e-mail: cristina.fdezdiego@unican.es

I. A. Carrascal · D. Ferreño $\cdot$ S. Diego $\cdot$ A. Casado LADICIM (Laboratory of Materials Science and Engineering), School of Civil Engineering, University of Cantabria, Avenida Los Castros 44, 39005 Santander, ,

Cantabria, Spain the DP to quantify the degradation of insulation solids over time. In this sense, this paper proposes the possibility of analyzing paper degradation through fracture toughness. This approach is different from the study of mechanical properties such as tensile strength or strain because it provides a tool for solving most practical problems in engineering mechanics, such as safety and life expectancy estimation of cracked structures and components which cannot to be considered through the traditional assessment of the mechanical resistance of the material. An accelerated thermal ageing of Kraft paper in mineral oil was carried out at $130{ }^{\circ} \mathrm{C}$ during different periods of time, to obtain information on the kinetics of the ageing degradation of the paper. Double-edged notched specimens were tested in tension to study their fracture toughness. The evolution of the load-displacement curves obtained for different ageing times at the ageing temperature of $130{ }^{\circ} \mathrm{C}$ was utilized to the determination of the stress intensity factor. Furthermore, different kinetic models based on this stress intensity factor were applied to relate its evolution over time as a function of the temperature. Finally, the correlation between the DP and stress intensity factor, which depends on the fiber angle, was also defined. 


\section{Graphic abstract}

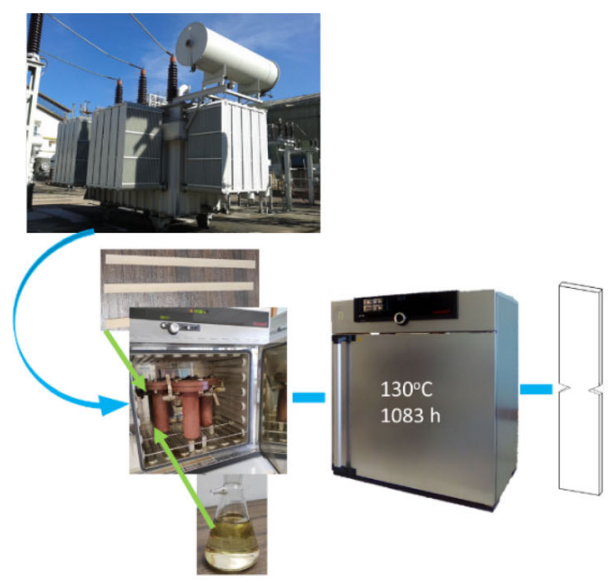

Keywords Kraft paper - Power transformer · Thermal ageing · Fracture toughness - Degree of polymerization $\cdot$ Mechanical properties

\section{Introduction}

Transformers are long run devices known as key parts of an electrical power system (Maharana et al. 2018; Karthik and Narmadhai 2020; Suwarno and Ritonga 2020). Nowadays, oil-immersed transformers, whose insulation system is composed of an insulating fluid (mineral oil, natural or synthetic ester) and a conductor insulation (Kraft, Crépe, DDP, Nomex®...) are widely used worldwide (Chen et al. 2020; Garelli et al. 2021). Cellulose insulants are the main solid insulator for the winding conductors, inter-winding, intercore and winding-to-earth insulation (Levchik et al. 1998; Rao and Jarial 2019) due to its excellent insulation performance and mechanical properties at elevated temperatures (Medina et al. 2017; Jusner et al. 2021).

During transformers' operation their paper and oil insulations are affected by many variables (temperature, moisture, oxygen, mechanical and electric stresses), provoking their degradation and affecting their dielectric, mechanical and chemical properties (Li et al. 2020). Although the degradation suffered by oil can be resolved through its treatment (filtration, dehumidification, purification) or replacement, paper deterioration can only be repaired by means of paper

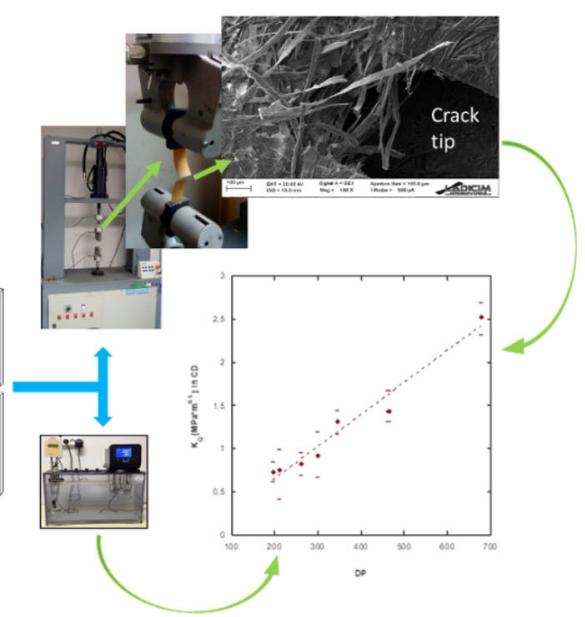

replacement which is critical for economic reasons (Łojewski et al. 2010; Medina et al. 2017). Therefore, the lifespan of a transformer is considered to be mainly defined by the insulation paper condition (Łojewski et al. 2010; Chen et al. 2020).

When insulation paper ages, depolymerization of the cellulose chain takes place which results in a decrease of its degree of polymerization (average number of glucose units per cellulose chain) and mechanical strength. Therefore, the insulation material becomes more brittle and carbonaceous and reduces its capability to withstand thermal, mechanical and electric stresses (Oommen and Prevost 2006a part I; 2006b part II; Vänskä et al. 2014).

The condition and remaining life of the winding insulating paper can be evaluated through indirect measurements (furaldeydes, gases, methanol or ethanol dissolved in the oil, energy dispersive spectroscopy, Fourier-transform infrared spectroscopy, differential thermal analysis...) and direct methods (degree of polymerization (DP), mechanical properties) (Arroyo et al. 2015; Saldivar-Guerrero et al. 2016; Suwarno and Ritonga 2020). These direct methods have been used to evaluate the compatibility of cellulose and new liquids, degradation, damage and ageing in different works (Hill et al. 1995; Li et al. 2016; Hosoya et al. 2018; Wang et al. 2019; Faiz et al. 2020). The end-of-life criteria applied to insulation paper is based on either a value of 200 for DP or retained tensile strength (20\%) as the decisive factor to determine the material lifespan. However, the need of high performance electrical insulation materials 
(Prevost and Oommen 2006; Chen et al. 2019; Jindal and Singh 2020; Xie et al. 2020), as well as new industrial drying processes have produced new dielectric materials in which the determination of DP has been found problematic (Lukic et al. 2021). Since the DP is a specific property of cellulose products (Marek and Szewczyk 2017), mechanical properties seem to be more suitable to quantify the insulation deterioration, working universally for almost all solid materials.

The most commonly used mechanical property for assessing the condition of the insulation paper is the tensile strength (Hill et al. 1995) which has been found to decrease proportionally to the DP (Medina et al. 2017). Experimental results on the thermal ageing of Kraft paper in different insulating liquids (mineral oil, natural ester and gas to liquid oil) using the DP and the tensile strength were reported by Suwarno and Ritonga (2020). The analysis of tensile strength and DP was applied by Maharana et al. (2018) to measure the mechanical strength and the intensity of chemical degradation of Kraft paper too. Their experiments on thermal ageing were performed for two different insulating oils (mineral oil and a nanofluid based on exfoliated hexagonal boron nitride). Maharana et al. found that the DP and the mechanical strength of the oil impregnated Kraft paper were proportional to each other. A linear correlation between tensile strength and methanol was also concluded by (Arroyo et al. 2015, 2017) who studied two paper/oil systems (standard wood Kraft paper and a thermally-upgraded Kraft paper) under ageing conditions at a large range of temperatures $\left(150-190{ }^{\circ} \mathrm{C}\right)$. They fitted their experimental data by means of a kinetic model, defined by Calvini, using the Arrhenius equation to

Table 1 Kraft paper properties

\begin{tabular}{lll}
\hline Property & Units & Value \\
\hline Grammage & $\mathrm{g} / \mathrm{m}^{2}$ & 149.3 \\
Thickness/5 sheets & $\mathrm{Mm}$ & 198 \\
Apparent density & $\mathrm{kg} / \mathrm{m}^{3}$ & 754 \\
Moisture & $\%$ & 6.3 \\
Tensile Index & $\mathrm{Nm} / \mathrm{g}$ & 108.4 \\
Ash & $\%$ & $<0.6$ \\
Aqueous extract conductivity & $\mathrm{mS} / \mathrm{m}$ & 1.5 \\
Dry breakdown strength in air & $\mathrm{kV} / \mathrm{mm}$ & 8.9 \\
\hline
\end{tabular}

Table 2 Mineral oil properties

\begin{tabular}{llc}
\hline Property & Units & Value \\
\hline Viscosity, $40{ }^{\circ} \mathrm{C}$ & $\mathrm{mm}^{2} / \mathrm{s}$ & 7.6 \\
Viscosity, $-30{ }^{\circ} \mathrm{C}$ & $\mathrm{mm}^{2} / \mathrm{s}$ & 730 \\
Pour point & ${ }^{\circ} \mathrm{C}$ & -63 \\
Flash point & ${ }^{\circ} \mathrm{C}$ & 154 \\
Water content & $\mathrm{mg} / \mathrm{kg}$ & $<20$ \\
Breakdown voltage & $\mathrm{kV}$ & $40-60$ \\
Acidity & $\mathrm{mg} \mathrm{KOH} / \mathrm{g}$ & $<0.01$ \\
Density, $20{ }^{\circ} \mathrm{C}$ & $\mathrm{kg} / \mathrm{dm}^{3}$ & 0.877 \\
\hline
\end{tabular}

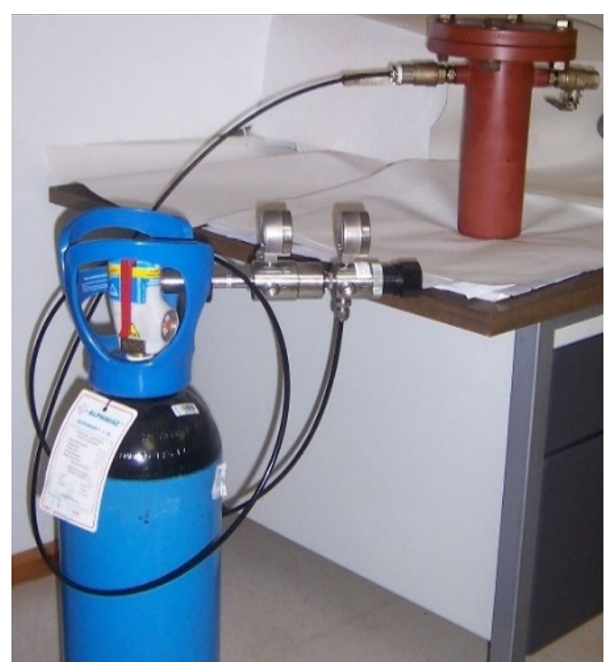

Fig. 1 Vessel for thermal ageing

Table 3 Ageing time

\begin{tabular}{llllllll}
\hline Temperature & \multicolumn{6}{l}{ Ageing time $(\mathrm{h})$} \\
\cline { 2 - 7 } & \multicolumn{2}{l}{ Samples } \\
\cline { 2 - 7 } & 0 & 1 & 2 & 3 & 4 & 5 & 6 \\
\hline $130{ }^{\circ} \mathrm{C}$ & 0 & 72 & 168 & 261 & 425 & 736 & 1083 \\
\hline
\end{tabular}

simulate the evolution of the mechanical properties' during thermal ageing. The applicability of methanol as an ageing marker was also evaluated by (Matharage et al. 2018), who studied the thermal ageing of an insulation paper immersed in synthetic ester at 80, 100 and $120^{\circ} \mathrm{C}$ using the tensile index. Furthermore, tensile strength has been used to measure the effect of accelerated thermal ageing of thermally upgraded 
Kraft and cellulose/aramid papers (Nomex 410 and 910) for improving the understanding of ageing in the mechanical properties of these relatively new materials (aramid papers) (Ranga and Chandel 2019; Arroyo et al. 2020). Arroyo-Fernández et al. obtained a quasilinear or master curve between the DP and the tensile strength for the cellulose-based paper. Moreover, they used the reduction in elongation over time to determine the state of solid insulation in power transformers, which demonstrated that this mechanical property can also be a suitable monitoring tool (Arroyo et al. 2020).

Even though there are different studies in which the suitability of mechanical properties to measure the deterioration undergone by a solid insulation has been demonstrated, to the best of these authors' knowledge, there are no contributions based on the use of fracture toughness to quantify the insulation solid deterioration and to predict its available lifespan. Fracture Mechanics is the discipline that explains how materials break. However, it is not a very common subject in the curricula. In practice, as an approximate approach, structural engineers use other material parameters for component design, such as the yield strength. The underlying idea is that if the stresses are substantially lower than the yield stress, failure is highly unlikely. However, the Fracture Mechanics is based on rigorous scientific criteria and requires specific experimental procedures to know in detail the way in which materials break.

Fracture toughness represents the ability of a cracked material to resist fracture. A reduced fracture toughness indicates that a material is susceptible of undergoing brittle fracture, while a high fracture toughness is associated with a ductile material. For brittle materials, the breaking condition establishes that the stress intensity factor equals the toughness of the material. Considering the significance of this novel approach, this paper is aimed to correlating the variations experienced by the fracture toughness with the degree of ageing of a Kraft paper. In addition, four kinetic models obtained from the bibliography have been applied to envisage the remaining lifespan of the Kraft paper using the stress intensity factor variation and their predictions were compared with those obtained from a classical model based on the DP and the load-displacement curves.

\section{Materials and thermal ageing}

\section{Material}

For this study, the Kraft paper, whose properties are showed in Table 1, was selected. This paper was cut into strips with a length of $90 \mathrm{~mm}$ and a width of $15 \mathrm{~mm}$. Due to the anisotropy of the paper, these strips were used to manufacture specimens with the two orientations of the paper: machine direction (MD) and cross machine (CD).

This work studies the deterioration of Kraft paper immersed in mineral oil (Table 2) during thermal ageing at $130{ }^{\circ} \mathrm{C}$. The degradation rate is evaluated using the degree of polymerization, through tensile tests (ultimate tensile strength, $\sigma_{R}$, strain under ultimate strength, $\varepsilon_{\mathrm{cm}}$, and energy per unit volume, $\left.E_{R}\right)$ and fracture toughness tests.

\section{Thermal ageing}

Kraft strips were placed into a stainless-steel vessel (Fig. 1) at pressure of $1 \mathrm{mbar}$ and temperature of $100{ }^{\circ} \mathrm{C}$ for $24 \mathrm{~h}$ in order to reduce its moisture content to $2 \%$.

Fig. 2 Deep, double-edged, notched specimen tested in tension for experiments

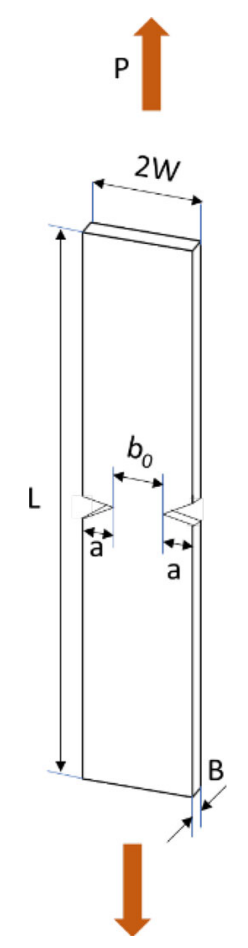


The dielectric mineral oil $(750 \mathrm{ml})$ was added to the vessel, and this was filled to $25 \%$ of its volume with nitrogen. Subsequently, the vessel was placed inside an air-forced oven and the temperature was maintained at $130{ }^{\circ} \mathrm{C}$ during the thermal ageing. The paper strips and oil were removed at different times (Table 3) for analysis. After the specific period of thermal ageing, six groups of paper samples with different deterioration levels were taken to characterize their properties (DP, ultimate tensile strength, strain under ultimate strength, energy consumed per unit volume and fracture toughness).

Traditional characterization of cellulose degradation

Kraft paper (90\% cellulose, 6-7\% hemicellulose and 3-4\% lignin) used for covering conductors in transformers is often characterized through the DP which represents the polymer chain average length of the cellulose (Bandara et al. 2016; Saldivar-Guerrero et al. 2016). Cellulose is a linear polymer made of the glucoside bond of the beta-D glucose monomer through the 1,4-glycoside bond (Wang et al. 2018). The thermal stress suffered by Kraft paper during thermal ageing results in a decrease of the DP (Vänskä et al. 2014). Consequently, the DP is recognized as an objective detection method to measure the rate of degradation. In this study, the DP of each group of specimens was measured following the viscometric method of the standard ASTM D4243. The viscosity-

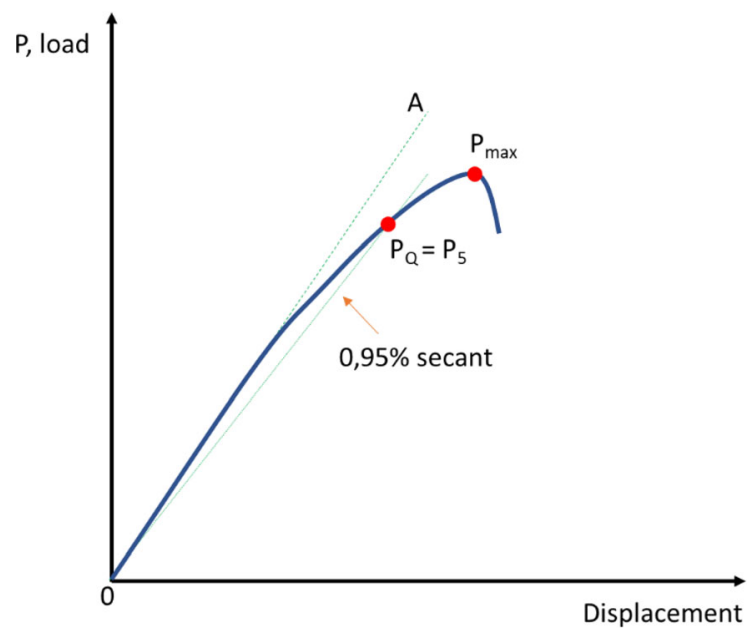

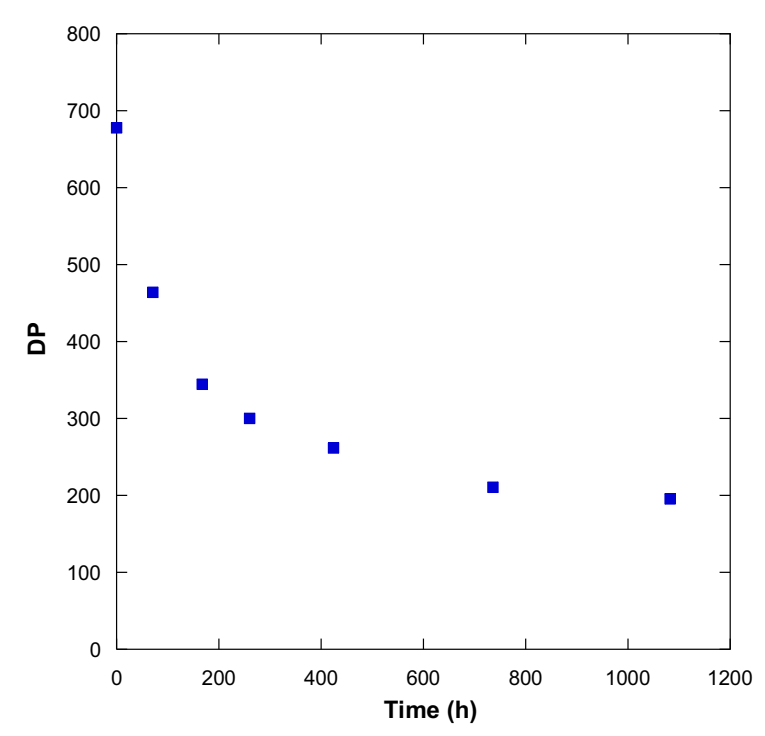

Fig. 4 Evolution of the DP as a function of time at $130{ }^{\circ} \mathrm{C}$

average DP was obtained based on measurements at $20{ }^{\circ} \mathrm{C}$ using an automatic viscometer equipped with a two-sphere Ubbelohde tube. Each specimen was first de-oiled using hexane. Subsequently, the milled paper was dissolved in a solution $(22.5 \mathrm{ml}$ of deionised water and $22.5 \mathrm{ml}$ of $1 \mathrm{M}$ solution of bis(ethylenediamine) copper (II) hydroxide). After dissolution of the paper in the solution through magnetic stirring, its specific viscosity was determined. Then, the intrinsic viscosity of the solution was deduced, and then the DP was obtained. The moisture of the sample, which is necessary for the previous calculations, was determined using the Karl Fischer titration.

Tensile tests were conducted using a servo hydraulic universal machine with an axial load cell of $\pm 1 \mathrm{kN}$ capacity, an actuator of $\pm 50 \mathrm{~mm}$ of dynamic stroke and equipped with pneumatic flat grips. The tensile tests were carried out according to ISO 1924-2 2009 and the parameters obtained in the test were the yield stress, $\sigma_{y}$, tensile strength, $\sigma_{\mathrm{R}}$, strain under ultimate strength, $\varepsilon_{\mathrm{cm}}$, and energy per unit volume at the tensile strength, $E_{R}$.

Both DP and tensile strength have been accepted to be equally important criteria to assess the deterioration on insulation papers (IEEE 2018). However, since DP is specific to cellulose products and tensile strength works for almost all solid materials used in transformers' insulation systems (Marek and Szewczyk

Fig. 3 Load-displacement curve mode I 
2017), the second one might be considered more suitable to establish a lifespan criteria.

Fracture toughness

Fracture toughness tests are carried out to quantify the resistance of a material to failure by cracking (Anderson 2005). The stress intensity factor $K_{I}$ measures the stress state near the tip of a crack or notch caused by a remote load or residual stresses. The constraint conditions at the tip of a crack are affected by the thickness of the component: thin components (like the pieces of paper characterized in this research) display pale stress conditions and thick components plane strain conditions. Plane strain conditions give the lowest fracture toughness value which is a material property. The critical value of stress intensity factor in tensile (mode I) loading measured under plane strain conditions is known as the plane strain fracture toughness, denoted $\mathrm{K}_{\mathrm{Ic}}$. When a test fails to meet the thickness and other test requirements that are in place to ensure plane strain conditions, the fracture toughness value produced is denoted $\mathrm{K}_{\mathrm{Q}}$ instead of $\mathrm{K}_{\mathrm{Ic}}$. The fracture process zone in a piece of paper corresponds to the region just ahead of the crack tip, where the fiber breakage and bond breakage concentrate when a cracked specimen is strained (Mai et al. 1995). Fracture toughness test were conducted following the $\mathrm{K}_{\mathrm{Ic}}$ procedure of the standard ASTM E1820-01.

Double-edge notched specimens (Fig. 2) with different notch sizes, were tested in tension. Following the recommendations of previous authors (Mai et al. 1995; Chen et al. 2016; Mao et al. 2017) the ligaments of the specimens in this research are in the range $6 \mathrm{~mm} \leq \mathrm{b}_{0} \leq 8 \mathrm{~mm}$, with specimen width $(2 \mathrm{~W})$ of $15 \mathrm{~mm}$. Each specimen's ligament was measured using an optical device coupled to a three-dimensional coordinate measuring machine (TESA MICRO-HITE 3D). Fracture toughness tests were carried out at room temperature a universal servo hydraulic test machine with an axial load cell of $\pm 1 \mathrm{kN}$ capacity, an actuator of $\pm 50 \mathrm{~mm}$ of dynamic stroke and equipped with pneumatic flat grips. The distance between the clamps was $60 \mathrm{~mm}$ and the crosshead speed to obtain the load-displacement curves was $6.67 \mathrm{~mm} / \mathrm{min}$.

The procedure to obtain $\mathrm{K}_{\mathrm{Ic}}$ established in the ASTM E 1820-01 standard requires the previous calculation of a conditional result, $\mathrm{K}_{\mathrm{Q}}$ which has to be obtained using the expression of the stress intensity factor provided by the standard introducing the critical load $\mathrm{P}_{\mathrm{Q}}$ obtained through the procedure depicted in Fig. 3: an auxiliary secant line with a slope.

$$
\left(\frac{\text { Load }}{\text { Displacement }}\right)_{5}=0.95 \cdot\left(\frac{\text { Load }}{\text { Displacement }}\right)_{0}
$$

Is constructed, $(\mathrm{Load} / \mathrm{displacement})_{0}$ being the slope of the tangent OA to the initial part of the curve. The intersection between the experimental curve and the auxiliary secant line determines $\mathrm{P}_{5}=\mathrm{P}_{\mathrm{Q}}$. $\mathrm{K}_{\mathrm{Q}}$ in deep, double-edged, notched specimens has been obtained using Eq. (2):

$K_{Q}=\frac{P_{Q}}{B \cdot \sqrt{W}} \cdot f\left(\frac{a}{W}\right)$

where $f(a / w)$ is a geometric factor given by (Anderson 2005):

$$
\begin{aligned}
f\left(\frac{a}{W}\right)= & \frac{\sqrt{\frac{\pi \cdot a}{2 \cdot W}}}{\sqrt{1-\frac{a}{W}}} \cdot\left[1.122-0.561 \cdot\left(\frac{a}{W}\right)-0.205\right. \\
& \left.\cdot\left(\frac{a}{W}\right)^{2}+0.471 \cdot\left(\frac{a}{W}\right)^{3}+0.190 \cdot\left(\frac{a}{W}\right)^{4}\right]
\end{aligned}
$$

The following conditions must be fulfilled to consider $\mathrm{K}_{\mathrm{Q}}$ as a geometry-independent measure of fracture toughness:

- The crack length must be in the range $0.45 \leq \mathrm{a} /$ $\mathrm{W} \leq 0.55$.

- The ratio (Pmax/PQ), where Pmax is the maximum load of the test, must be less or equal than 1.10.

- The thickness and length of the initial ligament must be higher than

$$
2.5 \cdot\left(\frac{K_{Q}}{\sigma_{Y}}\right)^{2}
$$

where $\sigma_{\mathrm{y}}$ is the $0.2 \%$ offset yield strength in tension.

It the test results fails to meet at least one of these three qualification requirements then $\mathrm{K}_{\mathrm{Q}}$ is not equal to $\mathrm{K}_{\mathrm{Ic}}$ (the linear elastic, plane-strain fracture toughness) but it remains as a valid characterization of the material fracture toughness for the geometric characteristics (thickness) of the specimen. 
Fig. 5 Kinetic models based on the DP

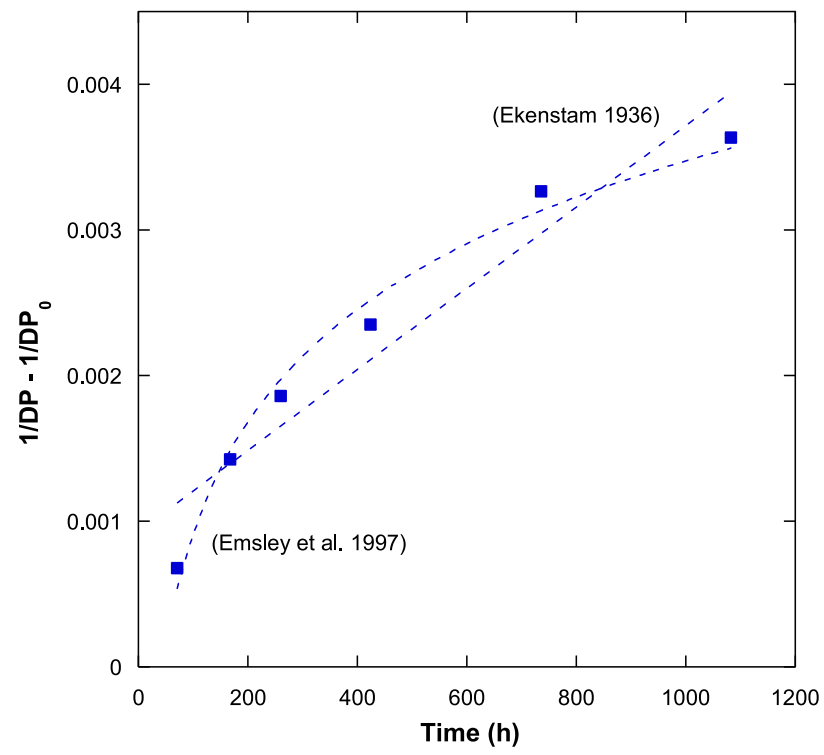

\begin{tabular}{|c|c|c|}
\hline Kinetic parameters & $\mathrm{R}^{2}$ & \\
\hline $\mathrm{k}=2.79 * 10^{-6}$ & 0.9230 & (Ekenstam 1936) \\
\hline $\mathrm{k}_{10}=9.54 * 10^{-6}$ & 0.9957 & (Emsley et al. 1997) \\
\hline $\mathrm{k}_{2}=2.46^{*} 10^{-3}$ & & \\
\hline
\end{tabular}

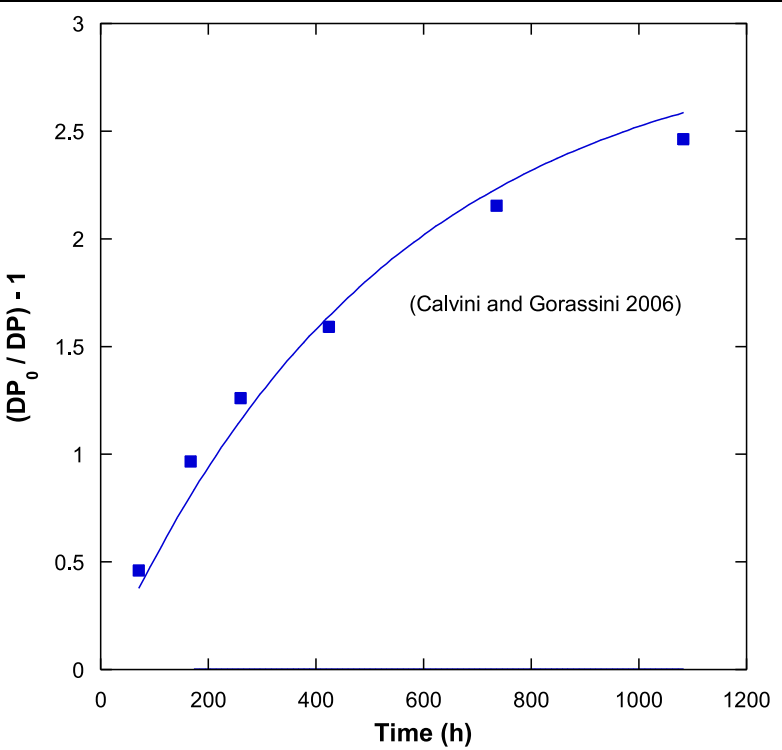

\begin{tabular}{|l|c|c|}
\hline Kinetic parameters & $\mathrm{R}^{2}$ & \\
\hline $\boldsymbol{h}_{\mathbf{0}} \cdot \boldsymbol{k}=1.49 * 10^{-3}$ & 0.9678 & (c) \\
\hline
\end{tabular}

Analysis and results

The degradation of Kraft paper in mineral oil has been characterized using the following properties: DP, tensile strength, $\sigma_{R}$, strain under ultimate strength, $\varepsilon_{\mathrm{cm}}$, and energy per unit volume, $\mathrm{E}_{\mathrm{R}}$.

\section{Degree of polymerization}

Figure 4 shows the evolution of the DP as a function of time. As can be seen, most of the reduction is concentrated in the first $200 \mathrm{~h}$ (the DP is reduced below $50 \%$ of its initial value). According to Bandara et al. (2016), this drastic drop is the result of the 
Fig. 5 continued

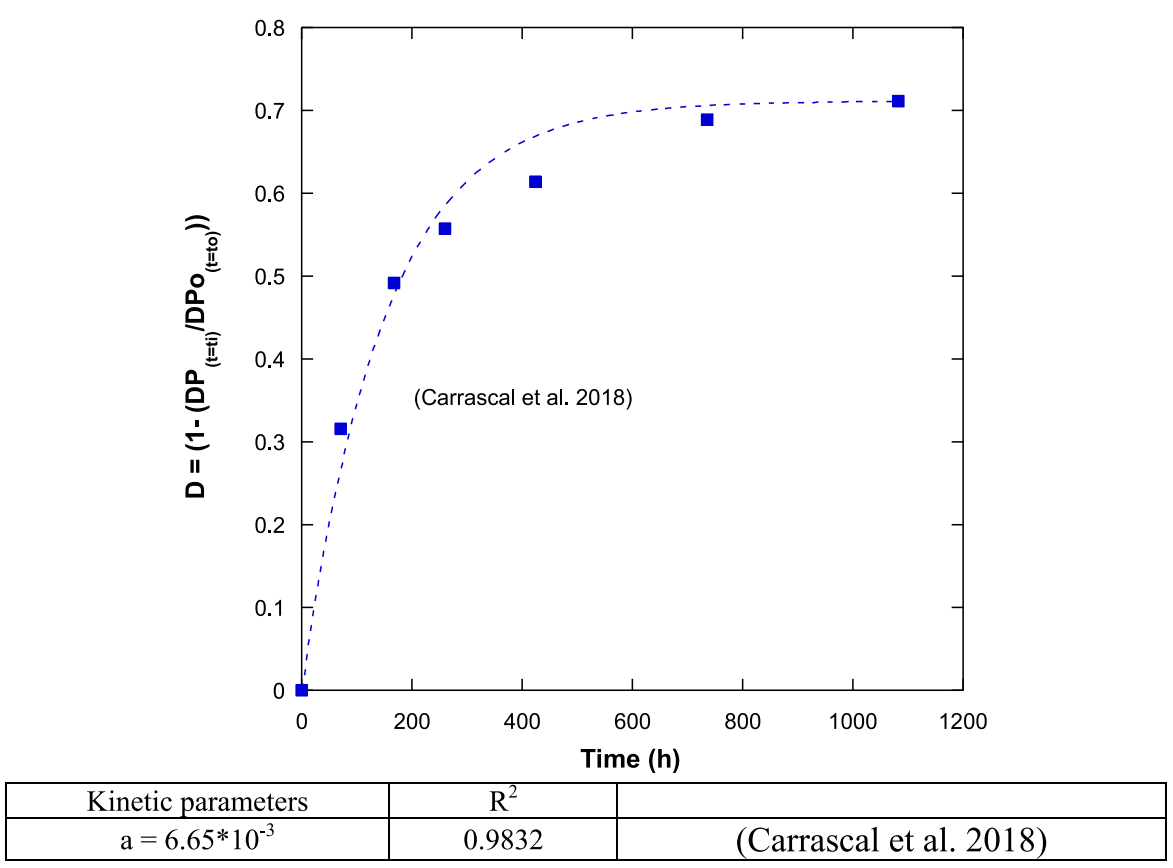

thermal stress generated at high temperature which breaks the bonding of the cellulose chains. In addition, it is considered that most of the water in cellulose is in the amorphous region which makes this region of cellulose deteriorates more quickly than the crystalline one.

Different kinetic models based on the DP have been proposed in the literature (Ekenstam 1936; Emsley et al. 1997; Calvini et al. 2008; Carrascal et al. 2018). These mathematical expressions relate the evolution of the DP over time as a function of the temperature. The selection of a suitable kinetic model to estimate the degradation suffered by the insulation solid in oilimmersed power transformers would make easier long-term planning for replacement of the oldest units, assist with the assessment of operational risks as uploading and support making decisions about maintenance and restoration. Once an end-of-life criterion is established, these models allow the remaining lifetime of the insulation paper to be estimated.

One of the kinetic models applied in this paper has been the one proposed by (Ekenstam 1936), that is the model in which many studies focused on thermal degradation of the paper used in power transformers are based:

$$
\frac{1}{D P}-\frac{1}{D P_{0}}=k * t
$$

where: $\mathrm{DP}_{0}$ is the degree of polymerization at the time of $0 \mathrm{~h}$; DP is the degree of polymerization at the time of $\mathrm{t}$; $\mathrm{k}$ is the constant rate of reaction and $\mathrm{t}$ is the ageing time (h).

The second model applied in this paper has been a second-order kinetic model (Emsley et al. 1997) which was proposed as a modification of Ekenstam model because it was observed that with the time, cellulose behavior deviates from the first-order kinetic model. In that case, the reaction rate is no longer constant, which is known as the leveling-off degree of polymerization (LODP). The Emsley approach is expressed as:

$\frac{1}{D P}-\frac{1}{D P_{0}}=\frac{k_{1_{0}}}{k_{2}} *\left(1-e^{-k_{2} * t}\right)$

where: $k_{10}$ and $k_{2}$ are temperature dependent constants.

In 2008 in their kinetic model Calvini et al. (2008) introduced the concept of $\mathrm{S}=\left(\mathrm{DP}_{0} / \mathrm{DP}\right)-1$ which represents the average number of chain scissions per cellulose chain unit during the time of degradation. Furthermore, they included the value of the levellingoff degree of polymerisation (LODP) into their kinetic law. Calvini et al. (2008) also considered that the cellulose polymer is composed of amorphous (a) and crystalline (c) regions and some weak bonds (w), establishing the following mathematical approach: 

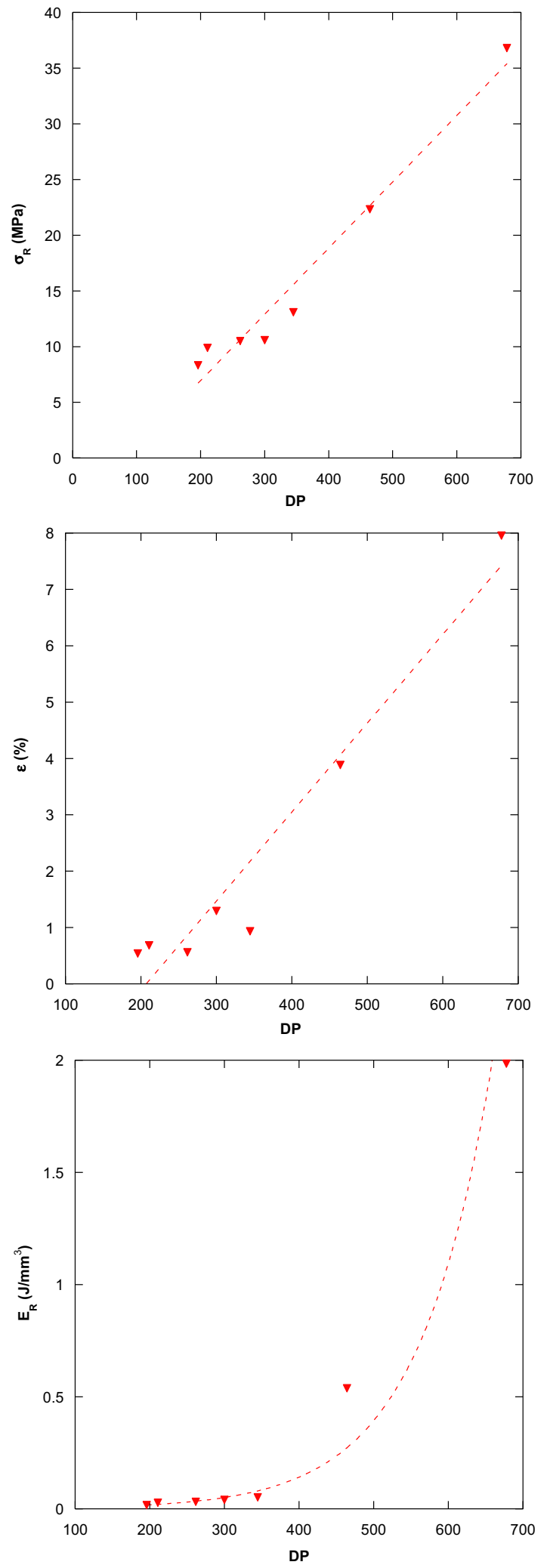

4Fig. 6 Mechanical properties vs DP in CD

$\begin{aligned} S= & n_{w}^{o} \cdot\left(1-e^{-h^{o} \cdot k_{w} \cdot t}\right)+n_{a}^{o} \cdot\left(1-e^{-h^{o} \cdot k_{a} \cdot t}\right)+n_{c}^{o} \\ & \cdot\left(1-e^{-h^{o} \cdot k_{c} \cdot t}\right)\end{aligned}$

where: $h_{0}$ is the initial amount of acidity, $n^{0}$ is the initial amount of overall scissile units (with suffixes a, glycosidic bonds in the amorphous region of cellulose; $\mathrm{c}$, glycosidic bonds in the crystalline region of cellulose; w, weak bonds). These authors discussed that the contribute of weak bonds was found to be negligible. Additionally, Calvini et al. (2008) established that the deterioration of crystalline regions emerges very slow, with a small effect on the rate constant of degradation of amorphous domains regions of cellulose, so that a long ageing period should be necessary to verify the mechanisms of cellulose decomposition. Since the ageing period applied in this paper has been only $1083 \mathrm{~h}$, it has been applied the simplified model proposed by Calvini et al. (2008):

$S=n^{o} \cdot\left(1-e^{-h^{o} \cdot k \cdot t}\right)$

Subsequently, Carrascal et al. (2018). defined a new kinetic model based on a damage parameter $\mathrm{D}$ which can be calculated using the DP or mechanic properties (rupture strength $\left(\sigma_{R}\right)$, strain under ultimate strength $\left(\varepsilon_{\mathrm{cm}}\right)$, energy consumed per unit volume $\left.\left(\mathrm{E}_{\mathrm{R}}\right)\right)$ values:

$D=1-\frac{D P_{i(t=t i)}}{D P_{0(t=0)}}$

$D=1-\frac{\text { Mechanicalproperty }_{i(t=t i)}}{\text { Mechanicalproperty }} y_{0(t=0)}$

where: $\mathrm{D}$ is the damage which can be obtained from the DPi or a Mechanical property ${ }_{i}$ value in any situation of time $(t=t i)$ and temperature $(T)$ and from $\mathrm{DP}_{0}$ or Mechanical property $y_{0}$, which are the values of the DP or the mechanical property of the new paper not aged.

The kinetic model expresses the evolution of a property (DP, $\sigma_{R}, \varepsilon_{\mathrm{cm}}, \mathrm{E}_{\mathrm{R}}$ ) as a function of the ageing time and the temperature at which thermal ageing takes place. 

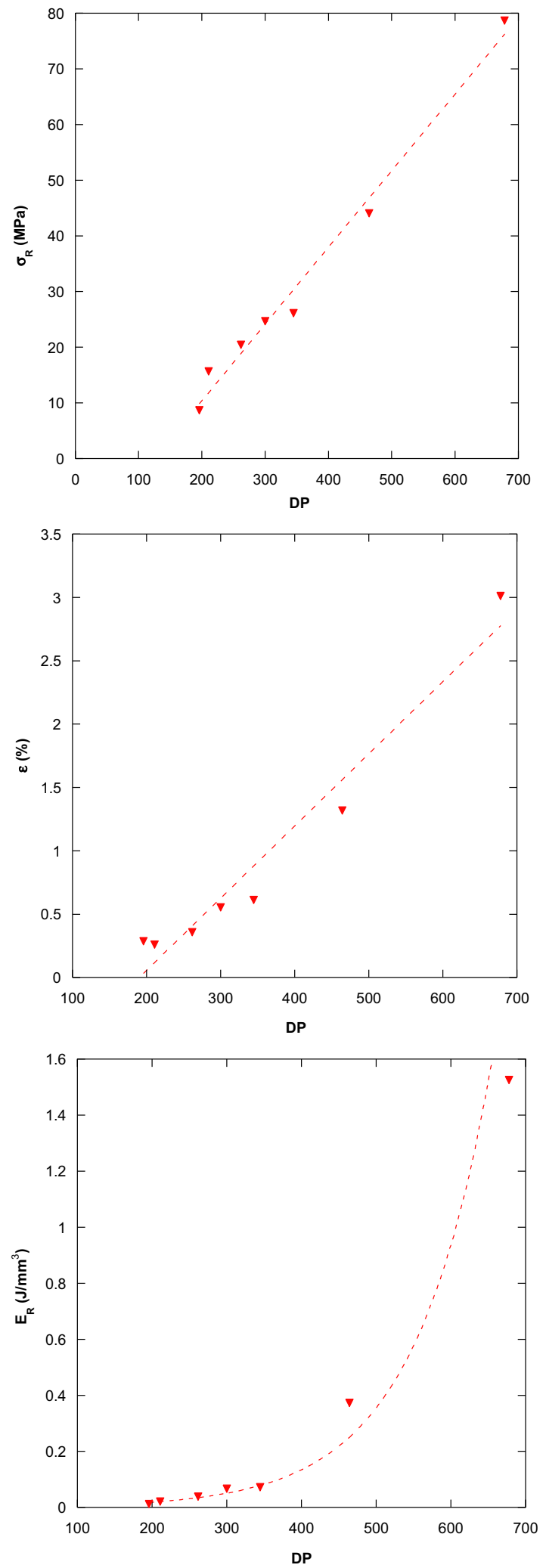

४Fig. 7 Mechanical properties vs DP in MD

Table 4 Mechanical properties vs DP of Kraft paper aged at $130{ }^{\circ} \mathrm{C}$

\begin{tabular}{lll}
\hline & Mathematical correlation & $\mathrm{R}^{2}$ \\
\hline \multicolumn{2}{c}{ Cross direction $(\mathrm{CD})$} & \\
$\sigma_{\mathrm{R}}$ & $\mathrm{DP}=16.25^{*} \sigma_{\mathrm{R}}+91.70$ & 0.9663 \\
$\varepsilon_{\mathrm{cm}}$ & $\mathrm{DP}=59.48^{*} \varepsilon_{\mathrm{cm}}+215.93$ & 0.9684 \\
$\mathrm{E}_{\mathrm{R}}$ & $\mathrm{DP}=93.56^{*} \ln \left(\mathrm{E}_{\mathrm{R}}\right)+580.88$ & 0.9562 \\
Machine direction $(\mathrm{MD})$ & \\
$\sigma_{\mathrm{R}}$ & $\mathrm{DP}=7.16^{*} \sigma_{\mathrm{R}}+127.45$ & 0.9927 \\
$\varepsilon_{\mathrm{cm}}$ & $\mathrm{DP}=167.57^{*} \varepsilon_{\mathrm{cm}}+197.48$ & 0.9761 \\
$\mathrm{E}_{\mathrm{R}}$ & $\mathrm{DP}=100.19^{*} \ln \left(\mathrm{E}_{\mathrm{R}}\right)+599.45$ & 0.9710 \\
\hline
\end{tabular}

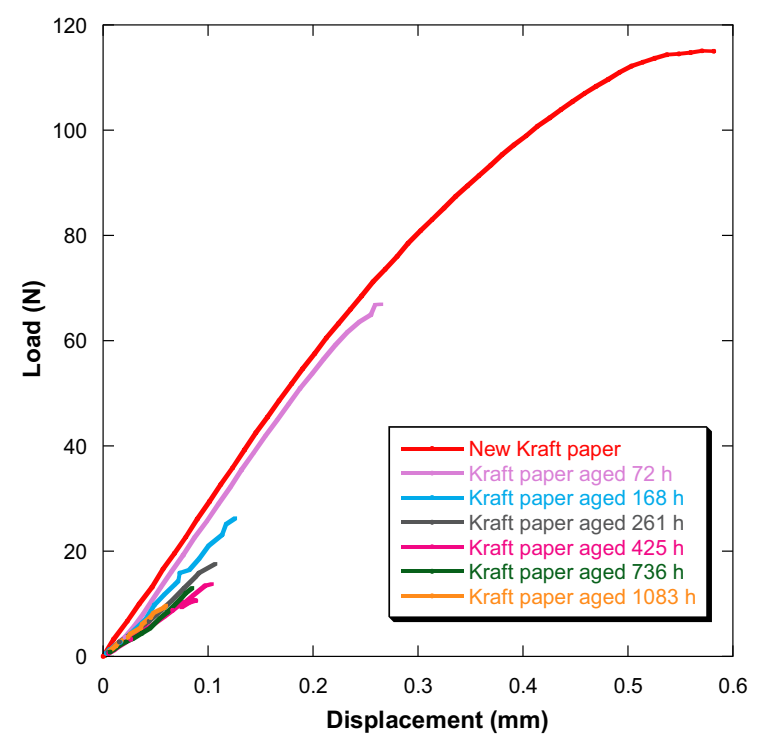

Fig. 8 Influence of the $t$ of ageing on load and displacement in MD

Property $_{i}=$ Property $_{0} \cdot\left(1-D_{\text {max }}(1-\exp (-a \cdot t))\right)$

where: $\mathrm{a}$ is a degradation rate that indicates the effect of oil temperature on the damage (D) suffered by insulation paper along the time; $\mathrm{D}_{\max }$ is the maximum value allowed for the damage.

These four models have been implemented considering the variation of DP during thermal ageing and the values of the different kinetic parameters $\left(\mathrm{k}, \mathrm{k}_{10}\right.$, 


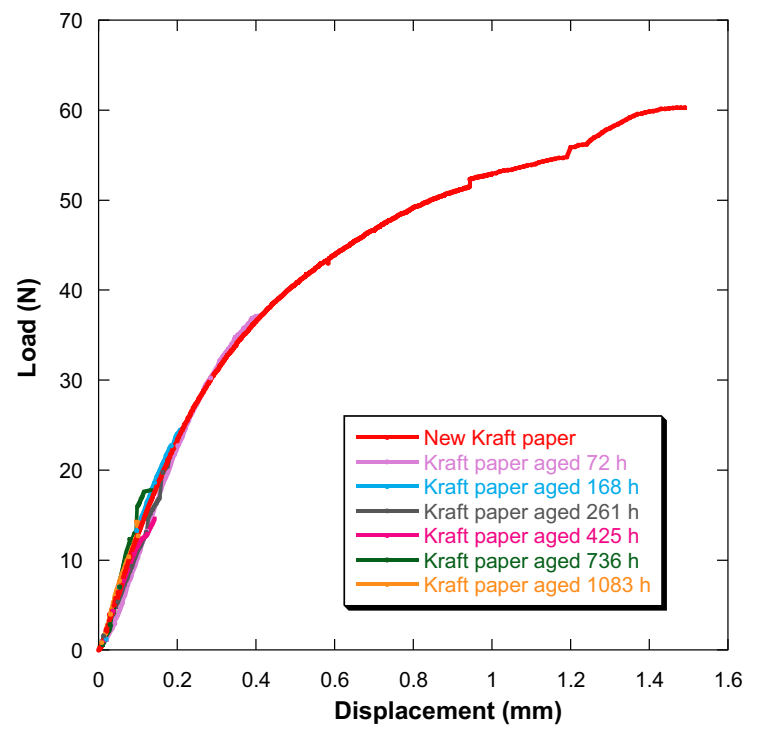

Fig. 9 Influence of the t of ageing on load and displacement in CD

$\mathrm{k}_{2}, \mathrm{~h}_{\mathrm{o}} \cdot \mathrm{k}$, a) from each model were calculated and are shown in the Fig. 5.

The kinetic parameters from the Calvini and Carrascal models (Calvini et al. 2008; Carrascal et al. 2018) have been obtained considering a leveling-off degree of polymerization (LODP) or critical degree of polymerisation of DPc $=200$ because this is often used as the end-of-life criterion (Lundgaard et al. 2007). As can be observed (Fig. 5), the model proposed by Emsley et al. (1997) provides the highest coefficient of determination R2 after the fitting of the free parameters.

Although the DP has proven to be an efficient tool to measure the loss of mechanical strength suffered by cellulosic materials such as the Kraft paper, it has also found some practical difficulties with its determination for some new papers after their drying (Lukic et al. 2021). Furthermore, the increasing interest in synthetic dielectric materials replacing cellulosic insulation (Prevost and Oommen 2006) enhances the establishment of alternative methods to DP to quantify the deterioration of insulation solids accurately. This role can be played by the properties obtained from tensile and fracture toughness tests, described hereafter.
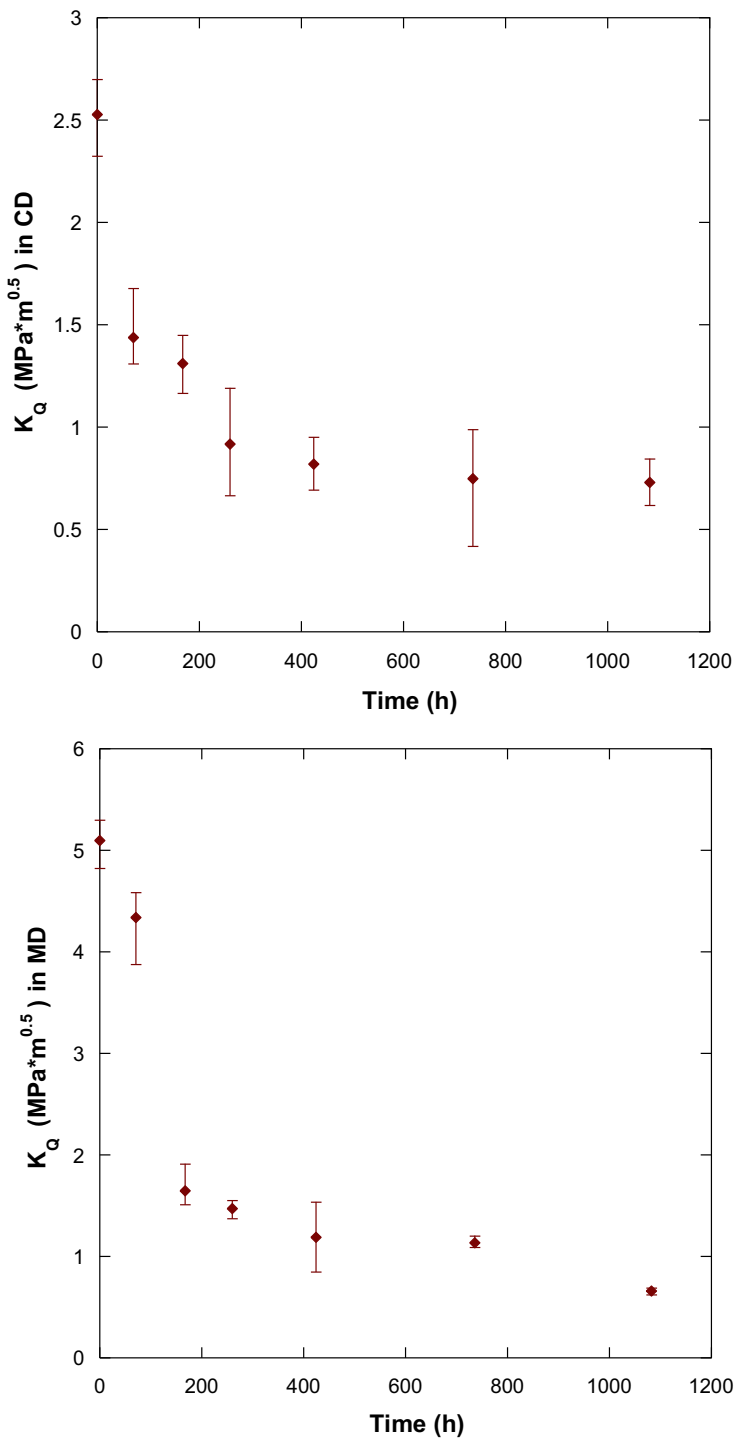

Fig. $10 K_{Q}$ in $M D$ and $C D$ as a function of the ageing $t$

Tensile tests

Firstly, it has been verified a strong anisotropy when the mechanical behavior of the original paper was analyzed as a function of the fiber direction angle (MD and $\mathrm{CD}$ ). The ultimate tensile strength in MD is two times the one measured in $\mathrm{CD}$, whereas the strain is half.

The correlation between a series of mechanical properties (ultimate tensile strength, $\sigma_{R}$, strain under ultimate strength, $\varepsilon_{\mathrm{cm}}$, and energy per unit volume, $E_{R}$ ), and the DP has been used as a proxy to assess the reliability of those properties to characterize the 


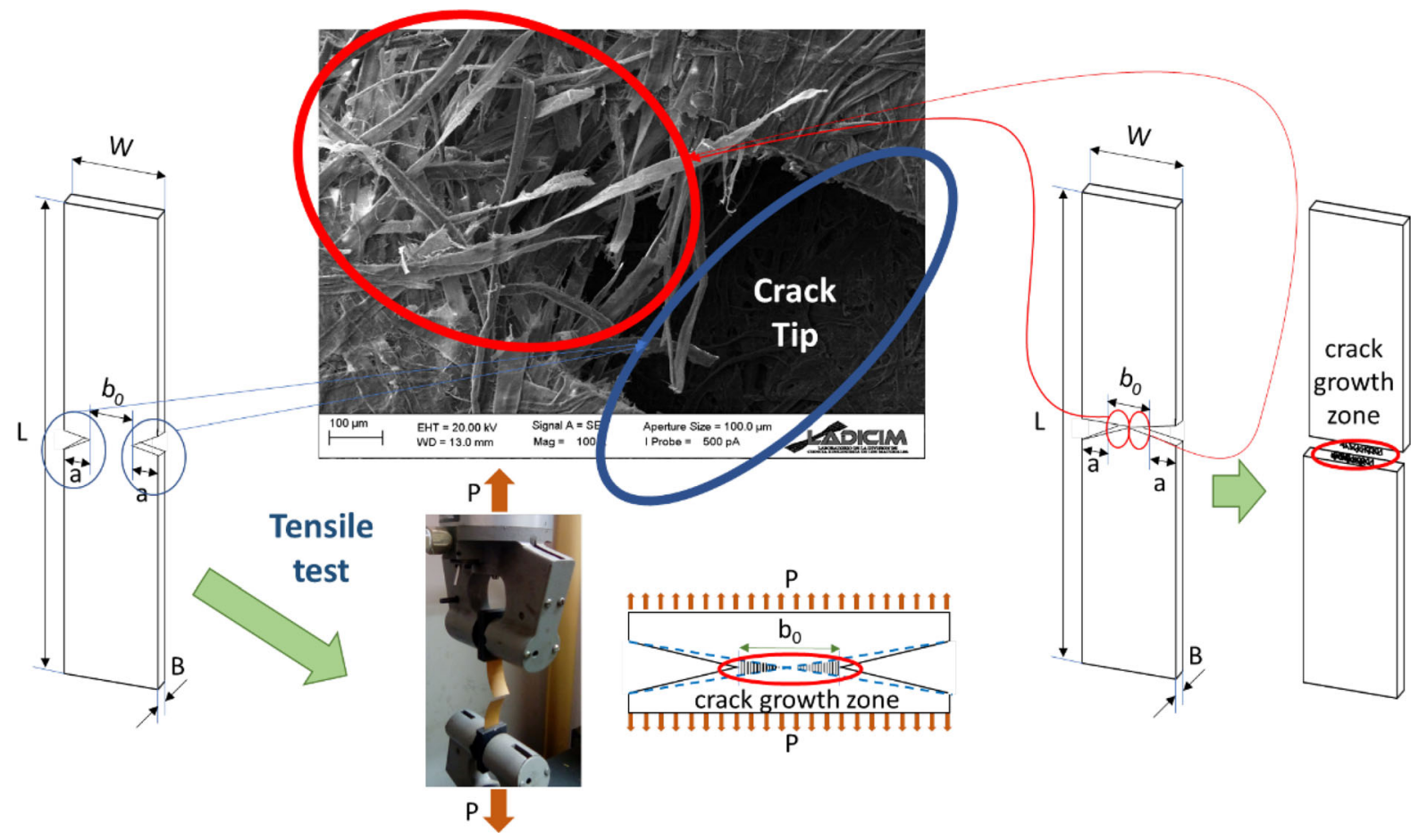

Fig. 11 Zone studied through fractographies

ageing of the Kraft paper previously aged at $130{ }^{\circ} \mathrm{C}$ in the laboratory.

Figures 6 and 7 show the correlation between the DP and these mechanical properties. Both $\sigma_{\mathrm{R}}$ and $\varepsilon_{\mathrm{cm}}$ display a suitable linear correlation whereas the relation between $E_{R}$ and the DP is sensibly exponential. Table 4 summarizes these mathematical relations and the correlation obtained for both fiber angle directions (MD and $\mathrm{CD}$ ).

\section{Stress intensity factor}

Once the high correlation existing between the DP and some mechanical properties $\left(\sigma_{\mathrm{R}}, \varepsilon_{\mathrm{cm}}\right.$ and $\left.\mathrm{E}_{\mathrm{R}}\right)$ had been verified, the following phase was to study whether fracture toughness can be applied as an alternative tool to quantify the deterioration suffered by the insulating materials used in the construction of power transformers.

Figures 8 and 9 show the evolution of the loaddisplacement curves obtained for different ageing times at the ageing temperature of $130{ }^{\circ} \mathrm{C}$ for MD and $\mathrm{CD}$ angle fiber.
It can be verified in Fig. 8 that the parameters of load and displacement clearly depend on the paper degradation. The rupture load and the displacement under this load are considerably affected by time. Similar behavior of properties loss was observed when fiber orientation was CD (Fig. 9).

The specimens analyzed in this work have not fulfilled the requirements explained previously to consider $\mathrm{K}_{\mathrm{Q}}$ as a geometry-independent measure of fracture toughness, consequently $\mathrm{K}_{\mathrm{Q}}$ is not equal to $\mathrm{K}_{\mathrm{Ic}}$ but it is a valid characterization of the material fracture toughness for the thickness of the specimen.

The stress intensity factor $\left(\mathrm{K}_{\mathrm{Q}}\right)$, whose evolution during thermal ageing is represented in Fig. 10, has been obtained using the load-displacement curves. It can be verified the ability of this mechanical parameter to quantify the influence of ageing on the material fracture strength. The $\mathrm{K}_{\mathrm{Q}}$ is reduced below $32 \%$ of its initial value in the first $200 \mathrm{~h}$. Subsequently, this parameter continues reducing its value below $13 \%$ of its initial value although it requires more than $800 \mathrm{~h}$ to achieve its final deterioration state.

The evolution of fracture strength was also verified through the study of crack growth zone where rupture 


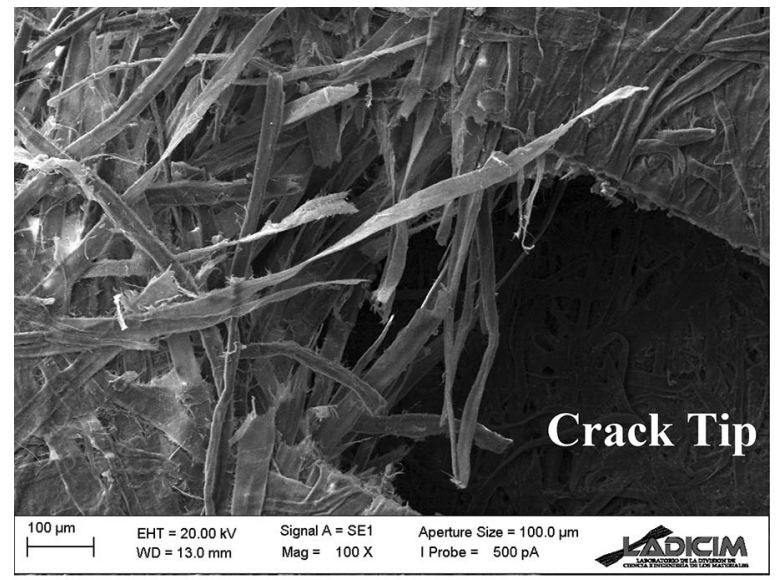

(a)

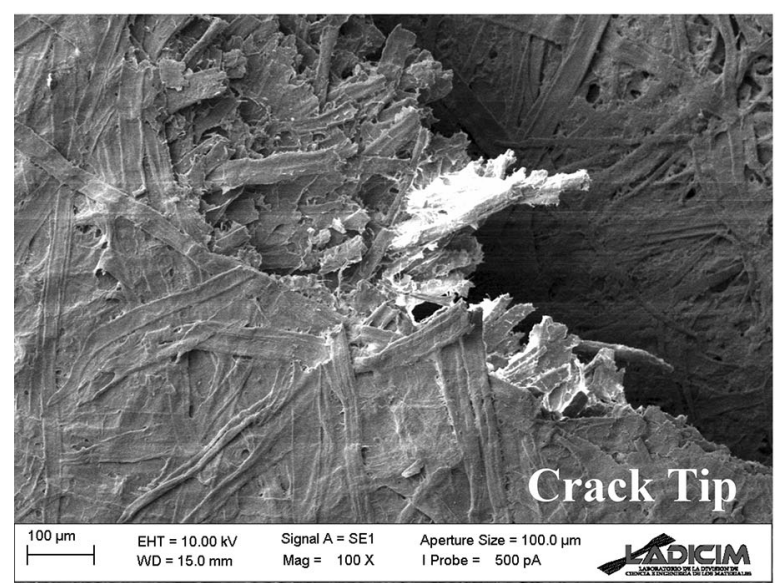

(c)

Fig. 12 a New Kraft paper $\left(\mathrm{K}_{\mathrm{O}}\right.$ in $\left.\mathrm{MD}=5.1 \mathrm{MPa}^{*} \mathrm{~m}^{0.5}\right)$, b Kraft paper aged during $72 \mathrm{~h}$ at $130{ }^{\circ} \mathrm{C}\left(\mathrm{K}_{\mathrm{Q}}\right.$ in $\mathrm{MD}=4.34 \mathrm{MPa}^{*} \mathrm{~m}^{0.5}$ ), c Kraft paper aged during $168 \mathrm{~h}$ at

Kraft strips happens (Fig. 11) using scanning electron microcopy (SEM). Paper strips were viewed using a Carl Zeiss-EVO MA 15 microscope, which uses as its electrons source a Lanthanum hexaboride filament with different detectors to distinguish secondary and backscattered electrons and characteristic X-rays (Oxford Instruments).

In the fractographies (Fig. 12), it can be verified that the fibres in the rupture section have undergone significant strain when the Kraft paper is new and at the beginning of the ageing ( $73 \mathrm{~h}$ of ageing) when the Kraft paper has suffered low deterioration (DP $>$ 460). It can be appreciated the huge strain suffered by insulation solid. In new and low-degraded paper specimens, the fibres undergone significant strain

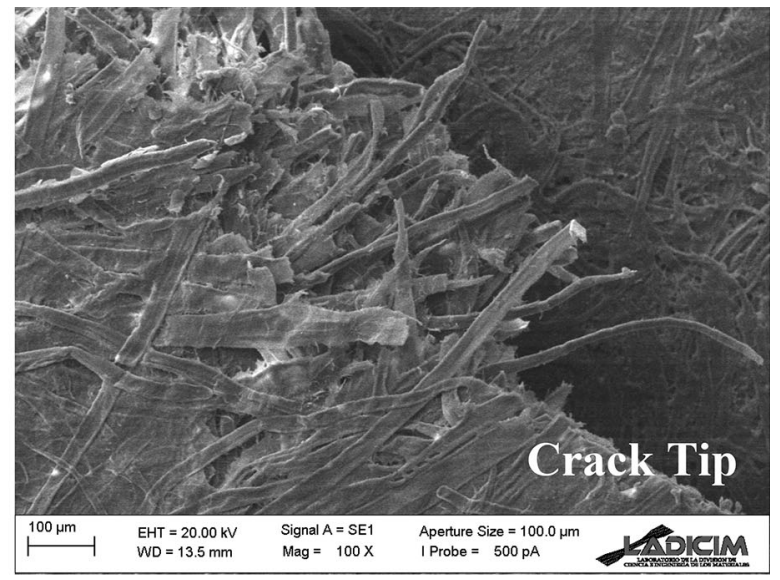

(b)

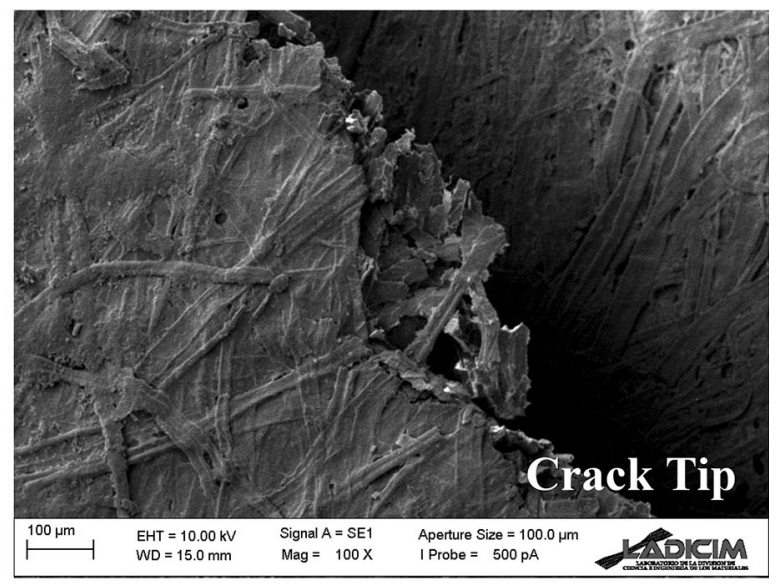

(d)

$130{ }^{\circ} \mathrm{C}\left(\mathrm{K}_{\mathrm{Q}}\right.$ in $\left.\mathrm{MD}=1.65 \mathrm{MPa}^{*} \mathrm{~m}^{0.5}\right)$, d Kraft paper aged during $1083 \mathrm{~h}$ at $130{ }^{\circ} \mathrm{C}\left(\mathrm{K}_{\mathrm{Q}}\right.$ in $\left.\mathrm{MD}=0.66 \mathrm{MPa}^{*} \mathrm{~m}^{0.5}\right)$

because they have sufficient strength to withstand the load applied, being the loosening of the interface between matrix and fiber the reason why a greater displacement in the material is achieved. In these first stages, the fibres' strength blocks crack propagation and there is a good interfacial bond between matrix and fibres, high loads during tensile test are required to increment crack growth and achieve Kraft's rupture. However, during thermal ageing, the fibres loss their mechanical resistance and then the failure occurs in the same plane than hemicellulose and lignin matrix. At this time, very low loads need to be applied in tensile test to achieve the rupture. These reduced loads are comparable with the matrix ones when resistance of insulation solid is considerable reduced (DP is close 
Fig. 13 Kinetic models based on the $\mathrm{K}_{\mathrm{Q}}$

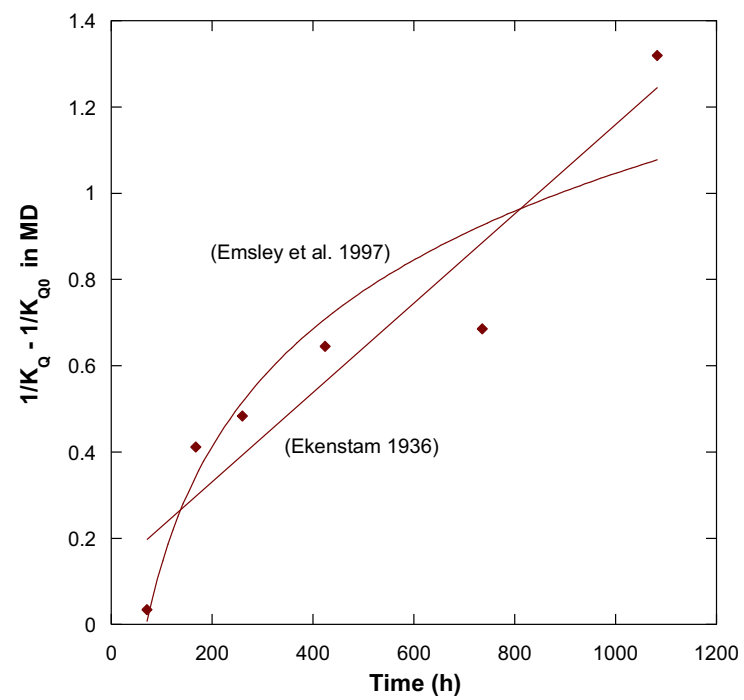

\begin{tabular}{|c|c|c|}
\hline Kinetic parameters & $\mathrm{R}^{2}$ & \\
\cline { 1 - 1 } $\mathrm{k}=1.21 * 10^{-3}$ & 0.8511 & (Ekenstam 1936) \\
\cline { 1 - 2 } $\mathrm{k}_{10}=1.67 * 10^{-3}$ & 0.8769 & (Emsley et al. 1997) \\
\hline $\mathrm{k}_{2}=8.01 * 10^{-4}$ & &
\end{tabular}

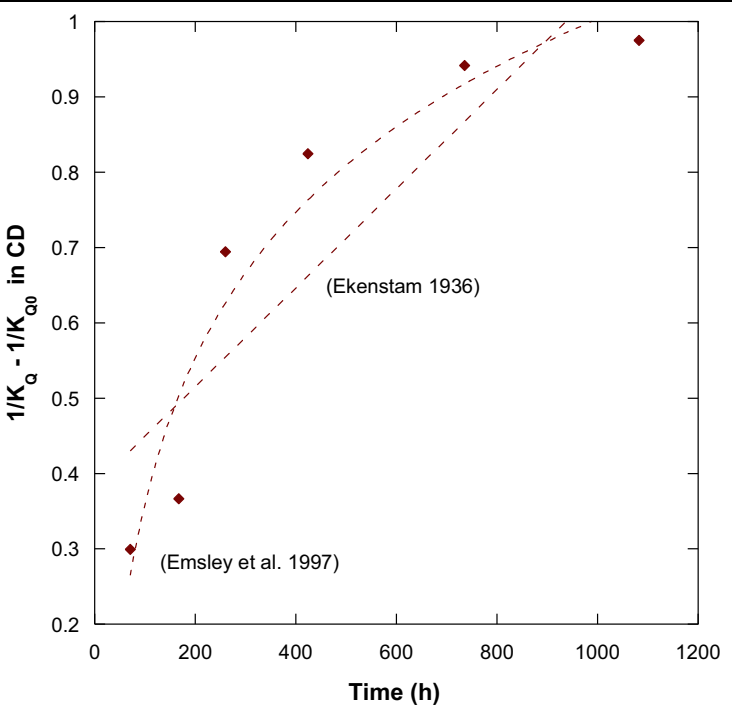

\begin{tabular}{|c|c|c|}
\hline Kinetic parameters & $\mathrm{R}^{2}$ & \\
\hline $\mathrm{k}=1.18^{*} 10^{-3}$ & 0.4804 & (Ekenstam 1936) \\
\hline $\mathrm{k}_{10}=3.88 * 10^{-3}$ & 0.9761 & (Emsley et al. 1997) \\
\hline $\mathrm{k}_{2}=3.87 * 10^{-3}$ & &
\end{tabular}

to 200). The fibres in the material have no strain which generates a fragile rupture. This change in the failure mode is critical because the crack propagation and final fracture in a fragile material takes place instantly which raises the partial discharges and short circuits occurrences.

It is known that kraft papers during their degradation at elevated temperature as it has been analyzed in this study, oxidation proceeds fast with accompanying hydrolysis. At an atomic scale these reactions favor the formation of carbonyl groups, glycosidic bond cleavage and hydrogen bond reorganization, which impacts on microfibrils' structure generating oxidation and shortening of cellulose chains, depolymerization and recrystallization. These changes at a microscopic level modify the insulation material properties at 
Fig. 13 continued

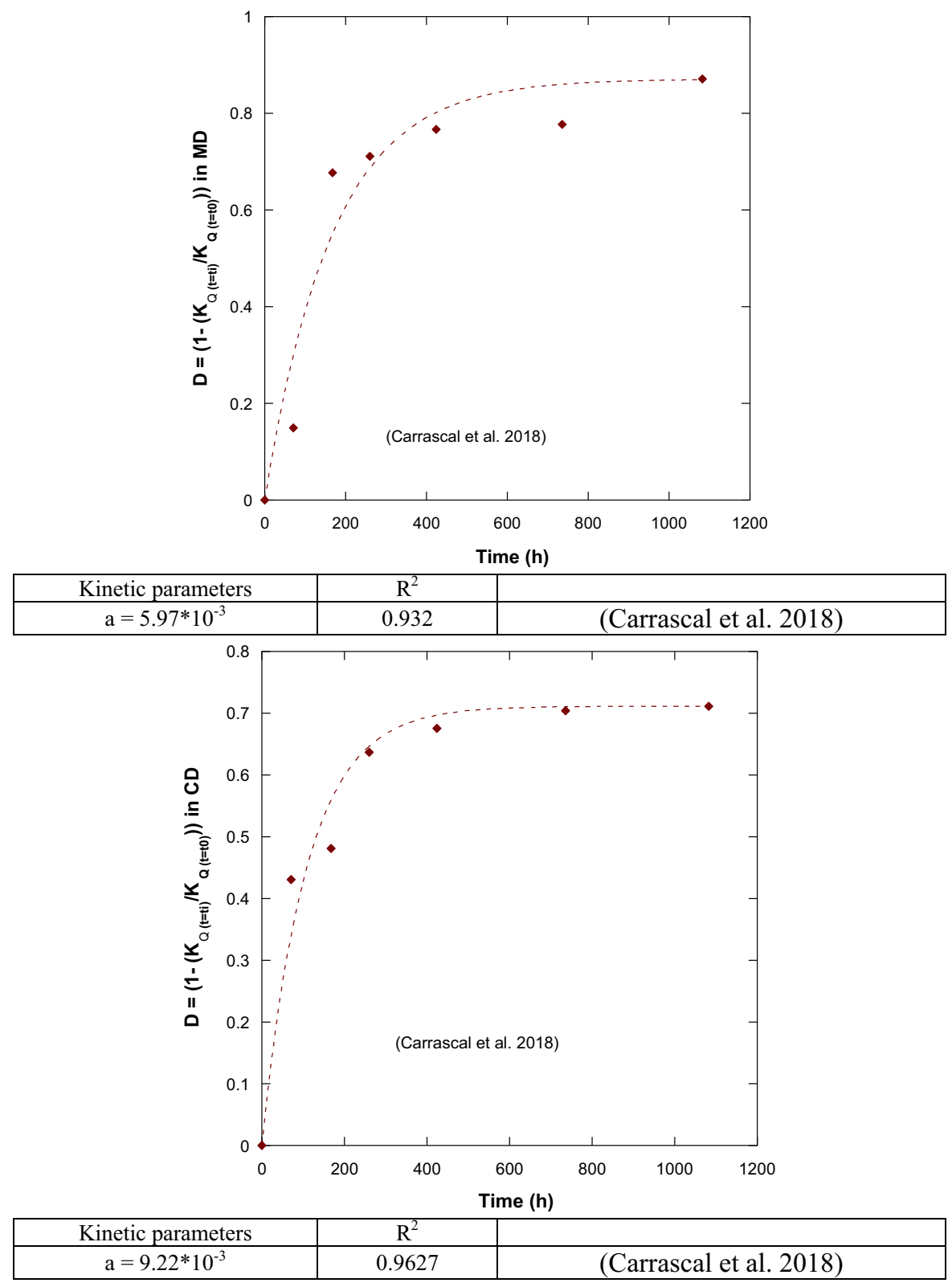

macroscopic scale, losing the insulation material properties (dielectric, mechanical) (Bagniuk et al. 2019).

Since $\mathrm{K}_{\mathrm{Q}}$ has been demonstrated to be a suitable mechanical parameter to quantify the influence of ageing on the material fracture strength at macroscopic level, kinetic models previously applied in this paper have been analyzed considering $\mathrm{K}_{\mathrm{Q}}$ instead of the DP. These expressions have allowed to relate the evolution of the $\mathrm{K}_{\mathrm{Q}}$ over time as a function of the temperature. Furthermore, the parameters of the kinetic models $\left(\mathrm{k}, \mathrm{k}_{10}, \mathrm{k}_{2}, \mathrm{~h}_{\mathrm{o}} \bullet \mathrm{k}\right.$, a) when these models are implemented using the stress intensity factor $\left(\mathrm{K}_{\mathrm{Q}}\right)$, have been calculated. The calculation of these parameters will make possible to estimate the deterioration of insulation materials in which the measurement of the DP has found some practical difficulties, allowing to carry out a suitable management of power transformers. 

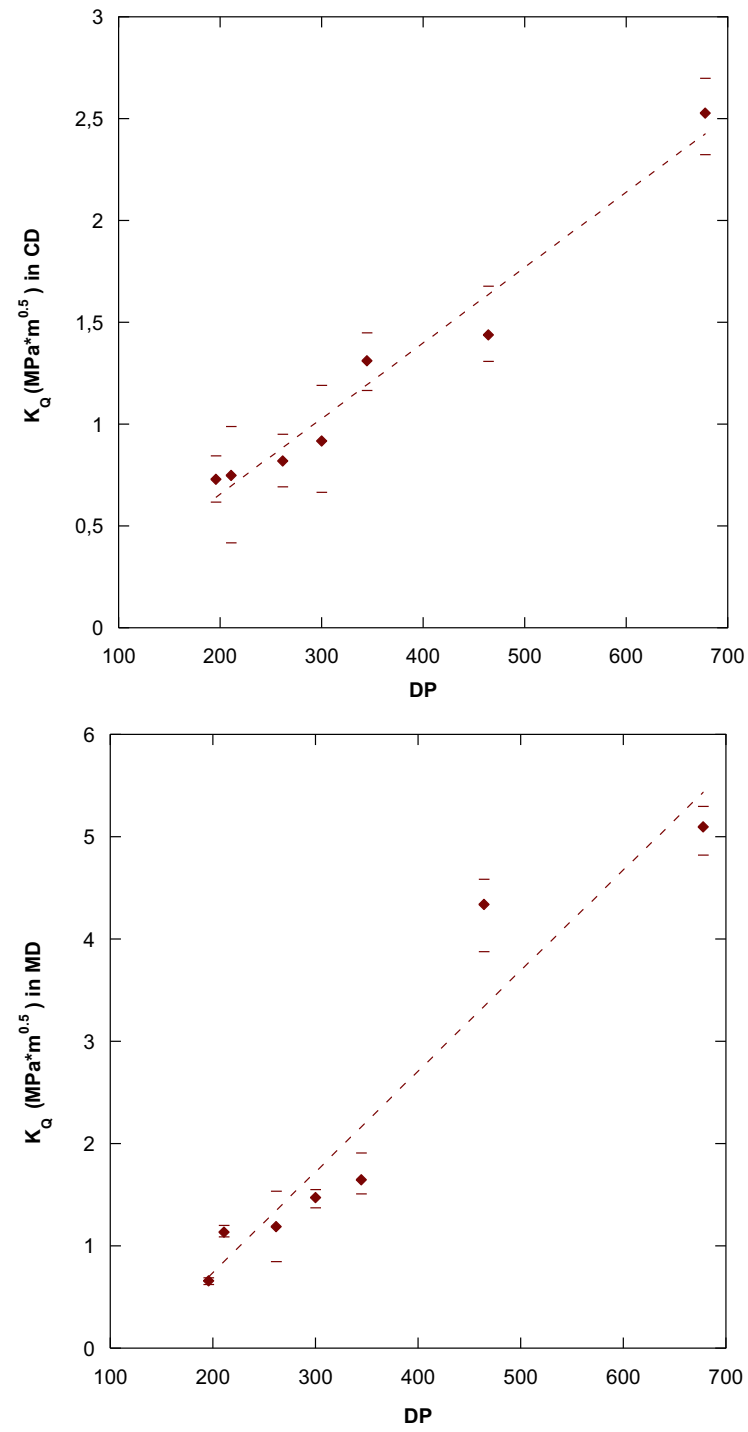

Fig. $14 K_{Q}$ vs DP in MD and CD

As can be observed (Fig. 13), the model proposed by Carrascal et al. (2018) provides the highest coefficient of determination R2 after the fitting of the free parameters when $\mathrm{K}_{\mathrm{Q}}$ in $\mathrm{MD}$ is considered. However, when $\mathrm{K}_{\mathrm{Q}}$ in $\mathrm{CD}$ was studied the highest coefficient of determination R2 was obtained by the model of Emsley et al. (1997).

The correlation between the DP and $\mathrm{K}_{\mathrm{Q}}$ was also obtained, see Fig. 14. As can be seen, there is a linear relation between the $\mathrm{DP}$ and $\mathrm{K}_{\mathrm{Q}}$ which depends on the fiber angle (MD and $\mathrm{CD}$ ).

The correlations between $\mathrm{DP}$ and $\mathrm{K}_{\mathrm{Q}}$ for the orientations $\mathrm{CD}$ and MD are shown in Table 5. The coefficient of determination R2 is higher than 0.9 in both cases. This result is an evidence in favor of the use of $\mathrm{K}_{\mathrm{Q}}$ to quantify the loss of mechanical strength of insulation paper in power transformers during thermal stress.

\section{Conclusions}

Although the DP is a property of cellulosic insulating materials widely used to determine the ageing of solid insulation in oil-immersed transformers, the development of new materials, as well as the application of new drying techniques during transformer manufacturing, have caused some practical difficulties in the DP measurement. For this reason, in this paper a novel approach based on the fracture toughness has been analyzed as alternative to quantify the ageing of insulation paper.

The double-edged notched specimens tested in tension to study their fracture toughness have demonstrated that this alternative approach is a valid characterization of the material degradation at macroscopic scale. Furthermore, even though the results obtained show that the specimens used in this paper did not fulfil the necessary requirements to consider the stress intensity factor $\left(\mathrm{K}_{\mathrm{Q}}\right)$ as a geometry-independent measure of fracture toughness, consequently $\mathrm{K}_{\mathrm{Q}}$ is not equal to the linear elastic, plane-strain fracture toughness $\left(\mathrm{K}_{\mathrm{Ic}}\right)$, but it is a suitable tool to estimate the degradation suffered by insulation solids. It has been found through the application of kinetic models, that the parameter $\mathrm{K}_{\mathrm{Q}}$ can be used to estimate the remaining life of insulation solids in power

Table 5 Stress intensity factor vs DP of Kraft paper aged at $130{ }^{\circ} \mathrm{C}$

\begin{tabular}{lcr}
\hline & Mathematical correlation & $\mathrm{R}^{2}$ \\
\hline Cross direction (CD) & $\mathrm{DP}=263.93 * \mathrm{~K}_{\mathrm{Q}}+30.52$ & 0.9656 \\
Machine direction (MD) & $\mathrm{DP}=93.22 * \mathrm{~K}_{\mathrm{Q}}+143.84$ & 0.9152 \\
\hline
\end{tabular}


transformers as a function of the temperature. Additionally, it has been concluded that the loss of insulation material fracture toughness is linearly related with the changes at a microscopic level in which oxidation and shortening of cellulose chains, depolymerization and recrystallization takes place (DP reduces its value considerably). These alterations at microscopic stage modifies the failure mode of Kraft paper which enhances crack propagation and final fracture, taking place instantly.

Acknowledgments The authors are grateful for the funding received to carry out this work from the State Scientific and Technical Research and Innovation Plan under the PID2019107126RB-C22grant agreement, financed by the Government of Spain.

Open Access This article is licensed under a Creative Commons Attribution 4.0 International License, which permits use, sharing, adaptation, distribution and reproduction in any medium or format, as long as you give appropriate credit to the original author(s) and the source, provide a link to the Creative Commons licence, and indicate if changes were made. The images or other third party material in this article are included in the article's Creative Commons licence, unless indicated otherwise in a credit line to the material. If material is not included in the article's Creative Commons licence and your intended use is not permitted by statutory regulation or exceeds the permitted use, you will need to obtain permission directly from the copyright holder. To view a copy of this licence, visit http://creativecommons.org/licenses/by/4.0/.

Funding Open Access funding provided thanks to the CRUECSIC agreement with Springer Nature.

\section{References}

Anderson TL (2005) Fracture mechanics: fundamentals and applications. CRC Press, London

Arroyo OH, Jalbert J, Rodriguez-Celis EM, Duchesne S, Morina B, Fofana I (2020) Changes in mechanical properties of impregnated Nomex papers 410 and 910 during accelerated aging. Polym Test 83:106358. https://doi.org/10.1016/ j.polymertesting. 2020.106358

Arroyo OH, Fofana I, Jalbert J, Ryadi M (2015) Relationships between methanol marker and mechanical performance of electrical insulation papers for power transformers under accelerated thermal aging. IEEE Trans Dielectr Electr Insul 22:3625-3632. https://doi.org/10.1109/TDEI.2015. 005386

Arroyo OH, Jalbert J, Fofana I, Ryadi M (2017) Temperature dependence of methanol and the tensile strength of insulation paper: kinetics of the changes of mechanical properties during ageing. Cellulose 24:1031-1039. https://doi. org/10.1007/s10570-016-1123-7
Bagniuk J, Pawcenis D, Conte AM et al (2019) How to estimate cellulose condition in insulation transformers papers? Combined chromatographic and spectroscopic study. Polym Degrad Stab 168:108951. https://doi.org/10.1016/j. polymdegradstab.2019.108951

Bandara K, Ekanayake C, Saha TK, Annamalai PK (2016) Understanding the ageing aspects of natural ester based insulation liquid in power transformer. IEEE Trans Dielectr Electr Insul 23:246-257. https://doi.org/10.1109/ TDEI.2015.004744

Calvini P, Gorassini A, Merlani AL (2008) On the rate of paper degradation: lessons from the past. Cellulose 15(2):193-203. https://doi.org/10.1007/s10570-007-91628

Carrascal IA, Fernández-Diego C, Casado JA, Diego S, Fernández I, Ortiz A (2018) Quantification of Kraft paper ageing in mineral oil impregnated insulation systems through mechanical characterization. Cellulose 25:3583-3594. https://doi.org/10.1007/s10570-018-17881

Chen Q, Kang M, Rong Z, Zong Z (2019) Effect of cellulose nanocrystals on the performance of oil-immersed transformer insulating paper. Bioresouces 14:6837-6850

Chen QJ, Kang MC, Xie QH, Wang JH (2020) Effect of melamine modified cellulose nanocrystals on the performance of oilimmersed transformer insulation paper. Cellulose 27:7621-7636. https://doi.org/10.1007/s10570-020-03305-4

Chen Y, Ridruejo A, González C, Llorca J, Siegmund T (2016) Notch effect in failure of fiberglass non-woven materials. Int J Solids Struct 96:254-264. https://doi.org/10.1016/j. ijsolstr.2016.06.004

Ekenstam A (1936) The behaviour of cellulose in mineral acid solutions: kinetic study of the decomposition of cellulose in acid solutions. BER 69:553

Emsley AM, Heywood RJ, Ali M, Eley CM (1997) On the kinetics of degradation of cellulose. Cellulose 4:1-5

Faiz N, Yang L, Han C, Bhutta MS, Hassan MAS, Farooq U, Ali SJ (2020) A modified $2^{\text {nd }}$ order kinetic model by including temperature effect and LODP of oil-impregnated paper under thermal degradation. In: $3^{\text {rd }}$ Int Conf Dielectr ICD, Valencia, Spain, pp 537-540. https://doi.org/10.1109/ ICD46958.2020.9342028

Garelli L, Ríos Rodriguez GA, Kubiczek K, Lasek P, Stepien M, Smolka J, Storti M, Pessolanid F, Amadeid M (2021) Thermo-magnetic-fluid dynamics analysis of an ONAN distribution transformer cooled with mineral oil and biodegradable esters. Therm Sci Eng Prog 23:100861. https://doi.org/10.1016/j.tsep.2021.100861

Hill DJT, Le TT, Darveniza M, Saha T (1995) A study of degradation of cellulosic insulation materials in a power transformer. Part 2: tensile strength of cellulose insulation paper. Polym Degrad Stab 49:429-435. https://doi.org/10. 1016/0141-3910(95)00100-Z

Hosoya T, Bacher M, Potthast A, Elder T, Rosenau T (2018) Insights into degradation pathways of oxidized anhydroglucose units in cellulose by $\beta$-alkoxy-elimination: a combined theoretical and experimental approach. Cellulose 25:3797-3814. https://doi.org/10.1007/s10570-0181835-y

IEEE C57.91-2011 - Guide for loading mineral-oil-immersed transformers and step-voltage regulators 
Jindal V, Singh J (2020) Development of new solid insulating material with aid of alkyl phenolic resin for a liquid-immersed transformer. Arab J Sci Eng 45:1357-1365. https:// doi.org/10.1007/s13369-019-03919-2

Jusner P, Schwaiger E, Potthast A, Rosenau T (2021) Thermal stability of cellulose insulation in electrical power transformers-A review. Carbohydr Polym 252:117196. https://doi.org/10.1016/j.carbpol.2020.117196

Karthik M, Narmadhai N (2020) A survey on natural esters based insulating fluid medium for transformer applications. Mater Today Proc. https://doi.org/10.1016/j.matpr.2020. 09.482

Levchik S, Scheirs J, Camino G, Tumiatti W (1998) Depolymerization processes in the thermal degradation of cellulosic paper insulation in electrical transformers. Polym Degrad Stab 61:507-511

Li S, Zhao X, Liao R, et al (2016) Study on ageing characteristics of insulating pressboard impregnated by mineralvegetable oil. In: Annu Rep - Conf Electr Insul Dielectr Phenomena, CEIDP, Toronto, Canada, pp 70-73. https:// doi.org/10.1109/CEIDP.2016.7785484

Li Y, Zhou K, Li ZR, Zhang QG (2020) Research on the electrical aging characteristics of oil-impregnated pressboard under partial discharges. IEEE Trans Dielectr Electr Insul 27:42-48. https://doi.org/10.1109/TDEI.2019.008304

Łojewski T, Miśkowiec P, Missori M, Lubańska A, Proniewicz LM, Łojewska J (2010) FTIR and UV/vis as methods for evaluation of oxidative degradation of model paper: DFT approach for carbonyl vibrations. Carbohydr Polym 82:370-375. https://doi.org/10.1016/j.carbpol.2010.04.087

Lukic J, Deville K, Lessard MC, Dreier L, Hohlein IA, Vrsaljko D, Peixoto A, Melzer L, Leward L, Ding H (2021) Changes of new unused insulating kraft paper properties during drying-Impact on degree of polymerization. Cigrè Sci Enginnering 20:161-170

Lundgaard L, Allan D, Höhlein IA, Clavreul R, Dahlund MO, Gasser HP, Heywood R, Krause C, Lessard MC, Saha TK, Sokolov V, Pablo A (2007) Ageing of cellulose in mineraloilinsulated transformers. Techn Broch 323:D1.01.10

Maharana M, Baruah N, Nayak SK, Sahoo N (2018) Electromechanical and chemical strength analysis of thermally aged nanofluid impregnated Kraft paper. In: Annu Rep Conf Electr Insul Dielectr Phenomena, CEIDP, Cancun, Mexico, pp 121-124. https://doi.org/10.1109/CEIDP. 2018.8544795

Mai YW, He H, Leung R, Seth RS (1995) In-plane fracture toughness measurement of paper. ASTM Spec Tech Publ 78:587-599. https://doi.org/10.1520/stp16407s

Mao R, Goutianos S, Tu W, Meng N, Yang G, Berglund LA, Peijs T (2017) Comparison of fracture properties of cellulose nanopaper, printing paper and buckypaper. J Mater Sci 52:9508-9519. https://doi.org/10.1007/s10853-0171108-4

Marek RP, Szewczyk R (2017) Revised sealed tube test procedure for thermal verification of liquid-immersed transformer insulation systems. Procedia Eng 202:147-158. https://doi.org/10.1016/j.proeng.2017.09.702

Matharage SY, Liu Q, Wang ZD, Wilson G, Krause C (2018) Aging assessment of synthetic ester impregnated thermally non-upgraded kraft paper through chemical markers in oil. IEEE Trans Dielectr Electr Insul 25:507-515. https://doi. org/10.1109/TDEI.2018.006833

Medina RD, Romero AA, Mombello EE, Rattá G (2017) Assessing degradation of power transformer solid insulation considering thermal stress and moisture variation. Electr Power Syst Res 151:1-11. https://doi.org/10.1016/j. epsr.2017.04.006

Mohan Rao U, Jarial RK (2019) Measurement of transformer solid insulation degradation using dilatometry and X-ray diffraction analysis. Meas J Int Meas Confed 131:701-705. https://doi.org/10.1016/j.measurement.2018.09.024

Oommen TV, Prevost TA (2006) Cellulose insulation in oilfilled power transformers: Part II-Maintaining insulation integrity and life. IEEE Electr Insul Mag 22:5-14

Prevost TA, Oommen TV (2006) Cellulose insulation in oilfilled power transformers: Part I-History and development. IEEE Electr Insul Mag 22:28-34. https://doi.org/10. 1109/MEI.2006.1618969

Ranga C, Chandel AK (2019) Influence of accelerated thermal ageing on the performance of alternative solid dielectrics for power transformers. Insight Non-Destructive Test Cond Monit 61:20-27. https://doi.org/10.1784/insi.2019.61.1.20

Saldivar-Guerrero R, Cabrera Álvarez EN, Leon-Silva U, Lopez-Gonzalez FA, Delgado Arroyo F, Lara-Covarrubias H, Montes-Fernandez R (2016) Quantitative analysis of ageing condition of insulating paper using infrared spectroscopy. Adv Mater Sci Eng. https://doi.org/10.1155/ 2016/6371540

Suwarno, Ritonga A (2020) Effects of thermal aging on the characteristics of kraft paper in various liquid insulating materials. In: Proceedings of the International Symposium on Electrical Insulating Materials. pp 15-24

Vänskä E, Luukka M, Solala I, Vuorinen T (2014) Effect of water vapor in air on thermal degradation of paper at high temperature. Polym Degrad Stab 99:283-289. https://doi. org/10.1016/j.polymdegradstab.2013.10.020

Wang D, Zhu Z, Zhang L, Qian Y, Su W, Chen T, Fan S, Zhao Y (2019) Influence of metal transformer materials on oilpaper insulation after thermal aging. IEEE Trans Dielectr Electr Insul 26:554-560. https://doi.org/10.1109/TDEI. 2018.007546

Wang Y, Wang Y, Jiang X (2018) The microscopic morphology of insulation pressboard: an image processing perspective. Cellulose 25:3051-3065. https://doi.org/10.1007/s10570018-1768-5

Xie F, Bao J, Zhuo L, Zhao Y, Dang W, Si L, Yao C, Zhang M, Lu Z (2020) Toward high-performance nanofibrillated cellulose/aramid fibrid paper-based composites via polyethyleneimine-assisted decoration of silica nanoparticle onto aramid fibrid. Carbohydr Polym 245:116610. https:// doi.org/10.1016/j.carbpol.2020.116610

Publisher's Note Springer Nature remains neutral with regard to jurisdictional claims in published maps and institutional affiliations. 